\title{
Hand dominance and the modification of the acoustically elicited startle response by a vibrotactile prepulse
}

\author{
CHRISTOPHER T. LOVELACE and TERRY D. BLUMENTHAL \\ Wake Forest University, Winston-Salem, North Carolina
}

\begin{abstract}
The acoustic startle eyeblink was measured in 10 right-handed and 10 left-handed college students, in response to an 85-dB SPL, $50-\mathrm{msec}$ broadband noise burst preceded on some trials by either a 50 - or a $250-\mathrm{Hz}$ vibrotactile prepulse to the hand $(20 \mathrm{msec}$ duration, $20 \mathrm{~dB} \mathrm{SL}, 50-\mathrm{msec}$ onset-toonset interval). Eyeblink amplitude and latency were generally facilitated by the prepulses, and latency was shorter when prepulses were presented to the dominant rather than the nondominant hand. Responding was more probable in the no-prepulse condition when subjects had the dominant hand in position to receive the prepulses. All subjects responded equally often when prepulses were applied to the dominant hand, but right-handers responded less often than left-handers when prepulses were applied to the nondominant hand. Females responded more often than males in the prepulse conditions, and vibrotactile thresholds were lower in females than in males.
\end{abstract}

When a stimulus of sufficient intensity and suddenness is presented to a subject, the subject will usually experience a startle response (Anthony, 1985; Graham, 1975). Such a response can be reliably elicited in humans and animals by, among other things, a sudden burst of white noise at intensities of $50 \mathrm{~dB}$ SPL or greater (Blumenthal \& Goode, 1991; Davis, 1984; Hoffman \& Ison, 1980). Animal research has shown that the startle response is a brainstem reflex, the motor component of which originates in the nucleus reticularis pontis caudalis (Davis, Gendelman, Tischler, \& Gendelman, 1982; Leitner, Powers, \& Hoffman, 1980). A suprathreshold stimulus (called a prepulse) occurring just before the startle-eliciting stimulus can modify the latency, amplitude, and probability of the eyeblink component of the startle response (Anthony, 1985; Graham, 1975). Leitner, Powers, and Hoffman (1979), Leitner, Powers, Stitt, and Hoffman (1981), and Leitner and Cohen (1985) have shown that, in rats, the midbrain areas of the lateral tegmentum and the inferior colliculus are involved in this reflex modification.

If the prepulse and startle stimulus are in different sensory modalities, reflex modification will vary as a function of prepulse lead time (the time from prepulse onset to startle stimulus onset, also called stimulus onset asynchrony). Graham (1980) found that with either a visual or an electrocutaneous prepulse at a lead time of less than $100 \mathrm{msec}$, there was facilitation of both the magnitude and the latency of the human acoustic startle eyeblink reflex. At lead times greater than $120 \mathrm{msec}$, there was

Correspondence should be addressed to Terry D. Blumenthal, Department of Psychology, Wake Forest University, Box 7778, Reynolda Station, Winston-Salem, NC 27109. inhibition of reflex magnitude but no change in reflex latency. Reiter and Ison (1977) found that a visual prepulse caused a slight facilitation of the amplitude of a blink elicited by an airpuff to the side of the face.

Blumenthal and Gescheider (1987), using a 20-dB SL vibrotactile prepulse presented to the hand, found increased amplitude and decreased latency of the human acoustic startle response at a 50 -msec lead time, and decreased amplitude and probability, but no effect on latency, for prepulses at a 200 -msec lead time, supporting Graham's (1980) findings. Blumenthal and Tolomeo (1989) presented 20-dB SL vibrotactile prepulses along with acoustic startle stimuli, and found increased response amplitude and decreased response latency at a $25-\mathrm{msec}$ lead time, and decreased amplitude at lead times of 150 msec or more. These data, taken together with the data obtained by using acoustic prepulses, show that at lead times of approximately 100 -msec or more, the prepulses in all modalities tested have a similar effect on the human acoustic startle response-inhibition of response amplitude and no effect on response latency.

However, at shorter lead times, differences between prepulse modalities are often found. At short lead times, prepulses in all modalities can cause decreased response latency to acoustic startle stimuli, but response amplitude is inhibited by acoustic prepulses and facilitated by visual, electrocutaneous, and vibrotactile prepulses. This suggests that, at short lead times, response amplitude inhibition occurs if the prepulse and startle stimulus are in the same modality, and facilitation occurs if they are in different modalities. One possible explanation for this modality effect is provided by Boelhouwer, Teurlings, and Brunia (in press), who presented acoustic prepulses before, during, or after electrically elicited eyeblink reflexes. They have explained their findings by concluding that the time 
between stimulus onsets (lead time) is less important than the difference in the time of arrival of neural input, generated by the stimuli, to the motor nucleus of the facial nerve, which innervates the muscles responsible for the eyeblink. If stimuli in different modalities have different transmission times, so that the time between stimulus onset and the arrival of neural activation at the facial nucleus is different across modalities, then prepulses in different modalities may have apparently different effects that are based solely on these differences in time of arrival of input to the facial motor nucleus. Boelhouwer et al. (in press) have therefore concluded that facilitation of startle at short lead times by stimuli presented in a sensory modality other than that of the startle stimulus may simply be due to differences in transmission time to the facial nucleus in the prepulse modality, with a summation of the input of the two stimuli at the facial nucleus.

There have been only two published studies to date of modification of the acoustic startle response by a vibrotactile prepulse in humans. In both, the prepulses were applied to the right hand of all of the subjects (Blumenthal \& Gescheider, 1987; Blumenthal \& Tolomeo, 1989). If there is differential responding that depends on whether prepulses are applied to the dominant or the nondominant hand, this could account for some of the overall variability in the results of such research. It is possible that this variability, if it does exist, could be reduced by administering the prepulses to the dominant (left) hand of the left-handed subjects. Furthermore, the results of the present study may provide support for inferences of physiological differences between right- and left-handers in the perception of vibrotactile stimuli and the modification of the startle response.

Researchers investigating the physical basis for hand preference have found few consistent physiological differences between right- and left-handers. However, one measurable difference is that the corpus callosum, which connects the two cerebral hemispheres, is somewhat larger in left-handers (Witelson, 1985). One hypothesis is that this is responsible for greater interhemispheric transfer (Haude, Morrow-Tlucak, Fox, \& Pickard, 1987) and, thus, less lateralization of certain brain functions (primarily verbal ones) in left-handers (Perelle, Ehrman, \& Manowitz, 1987). It has been shown that left-handers are not as good at performing tasks involving lower level cognitive processes as right-handers are, and that this difference is not found for tasks involving higher level functions (Fogliani, Fogliani-Messina, Barletta, \& Caruso, 1982). The question is, do differences exist between right- and left-handers in areas caudal to even these lower level areas of cognitive processing? The results of the present study could illustrate differences in the processing of sensory input as rostral as the midbrain, where startle modification effects are coordinated (Leitner \& Cohen, 1985; Leitner et al., 1979, 1981), and as caudal as the pons, where the motor components of the startle response originate (Davis, 1984).

Blumenthal and Gescheider (1987) investigated the effect of a $55-\mathrm{Hz}$ vibrotactile prestimulus applied to the thenar eminence of the right hand on startle elicited by an auditory stimulus. They found that prepulses at a 50msec lead time tended to facilitate responding, as was shown by increased amplitude and reduced latency of the startle eyeblink reflex. It was expected that these results would be replicated in the present study. Our main purpose in the present study was to see whether there would be differential responding to a startle-eliciting stimulus between right- and left-handed subjects, and to see how the responses would be affected by either a $50-$ or a $250-\mathrm{Hz}$ vibrotactile prepulse applied to the dominant and nondominant hand of each subject.

\section{METHOD}

\section{Subjects}

The subjects were 20 undergraduate college students, 5 each of right- and left-handed males and females, with an average age of 19 years, 2.5 months. The Edinburgh Handedness Inventory (Oldfield, 1971) was administered to approximately 250 introductory psychology students to assess the degree of right- or left-handedness for each student. Scores on the inventory ranged from -100 (very left-handed) to +100 (very right-handed). The few students with very negative (left-handed) scores (ranging from -20 to $-100 ; M=$ $-78.37, S D=24.23$ ) were given the opportunity to participate, as were a random sample of the large number of students scoring +100 .

\section{Stimuli}

The startle-eliciting stimulus was a 50-msec long, 85-dB SPL (relative to .0002 dynes $/ \mathrm{cm}^{2}$ ) broadband noise burst with a .1 -msec rise/fall time. There were two vibrotactile prepulse conditions, each prepulse being $20 \mathrm{msec}$ long, with a rise/fall time of $5 \mathrm{msec}$. One prepulse had a frequency of $50 \mathrm{~Hz}$, and the other had a frequency of $250 \mathrm{~Hz}$. Prepulse intensity was $20 \mathrm{~dB}$ above the psychophysical vibrotactile threshold of each subject. ${ }^{1}$ Prepulses were presented with a 50-msec lead time, measured from prepulse onset to startle stimulus onset. The intertrial interval averaged $20 \mathrm{sec}$, randomly ranging from 15 to $25 \mathrm{sec}$. A no-prepulse control condition was also included.

\section{Apparatus}

The vibrotactile prepulses were delivered with a Ling 203B shaker (vibrator) with an attached $3-\mathrm{cm}^{2}$ circular contactor. Two wooden seats with attached desks (one right-handed and one left-handed) were prepared so that the vibrator could be positioned beneath the desktop. The contactor surface was level with that of a Plexiglas plate installed in the center of the desk, its surface even with that of the desk. The plate had a $4.35-\mathrm{cm}^{2}$ hole in its center. There was a 1.0-mm gap between the edge of the contactor and the edge of the plate. The area of the hole through which the contactor protruded was the same for each desk. Vibration intensity was measured with an Endevco Model 2221D accelerometer (attached to the post between the contactor and the vibrator). This was connected to an Endevco Model 2721B charge amplifier and monitored with a Fluke Model $8050 \mathrm{~A}$ voltmeter.

Two Coulbourn precision signal generators, Model S81-06, generated the sinusoidal tones used to drive the vibrator. The startleeliciting stimuli were produced with a Coulbourn noise generator, Model S81-02. Each of these signals was activated by using Coulbourn selectable envelope shaped rise/fall gates, Model S84-04, which were also used to set the rise/fall times, and amplified through Coulbourn audio mixer/amplifiers, Model S82-24. The startle stimuli were further amplified through a Yamaha stereo amplifier and delivered through an Onkyo loudspeaker, Model S-30, located $1.5 \mathrm{~m}$ in front of the subject. The startle stimulus intensity was calibrated 
by presenting a steady-state signal to the loudspeaker, and it was measured with a Quest Electronics 215 sound-level meter. Rise/fall gates were activated by using an Apple Macintosh SE computer and a MacPacq MP10 interface.

Startle eyeblink responses were detected with SensorMedics skin electrodes $(\mathrm{Ag} / \mathrm{AgCl})$, which were attached to the face just below the left eye. These electrodes were connected to a Coulbourn highgain bioamplifier, Model S75-01, passing 90 - to $250-\mathrm{Hz}$ signals. The EMG signals were then sent through a Coulbourn contourfollowing integrator, Model S76-01 (time constant $=15 \mathrm{msec}$ ), and then to a Coulbourn adjustable gain amplifier, Model S79-02. This output was sampled once every millisecond for $500 \mathrm{msec}$ by a MacPacq interface, and this digital output was sent to a Macintosh SE computer, where each trial was recorded for later analysis.

\section{Procedure}

Each subject attended two sessions exactly 1 week apart, one with the prepulses applied to the right hand and another with the prepulses applied to the left hand. The order of these sessions was counterbalanced. After the subject filled out an informed consent form, the area just below the subject's left eye was cleaned with alcohol. A reference electrode was then attached to the subject's left arm just below the elbow, and two electrodes were attached to the subject's face just under the left eye-one directly below the pupil and one just temporal to that. The subject sat with the arm resting comfortably on the desk, the thenar eminence of the hand resting on the contactor surface. The subject was told not to move this hand at all until the end of the experiment.

The vibrotactile threshold for each subject was determined according to the two-interval forced-choice tracking method, by using $20-\mathrm{msec}, 50-\mathrm{Hz}$ vibrotactile pulses. The subject sat with one hand resting on the contactor and used the other hand to operate two buttons on a small box, each of which corresponded to a different light. For each trial of the threshold tracking procedure, one light would come on for $20 \mathrm{msec}$ and then go off; $1 \mathrm{sec}$ later, the other light would do the same. Paired with one of the lights was a 20-msec vibrotactile stimulus. The subject was told to respond by pressing the button corresponding to the light with which the vibrotactile stimulus was presented. The subject was given $2 \mathrm{sec}$ to respond, and there was a 2-sec delay between trials. Since time constraints for each session prevented finding thresholds for both the $50-\mathrm{Hz}$ and the $250-\mathrm{Hz}$ stimuli, the $50-\mathrm{Hz}$ stimulus was used throughout this procedure. It was expected that the resultant threshold value would be greater than it would if the $250-\mathrm{Hz}$ stimulus were used, because as stimulus frequency increases up to approximately $200 \mathrm{~Hz}$, threshold decreases (Pertovaara \& Linnonkoski, 1986), and this ensured that the intensity of the $250-\mathrm{Hz}$ prepulse would not be so low that it would not be perceived on each prepulse trial.

After determination of the vibrotactile threshold, the intensity of the vibrotactile stimuli was increased by $20 \mathrm{~dB}$, relative to $1.0-\mu \mathrm{m}$ displacement of the vibrator contactor. Trials were presented in 20 blocks of 3 trials each, with each block consisting of a no-prepulse control trial, a $50-\mathrm{Hz}$ prepulse trial, and a $250-\mathrm{Hz}$ prepulse trial, presented in random order within each trial block. These orders were also varied from 1 trial block to the next. After 60 trials, the electrodes were removed. After the second session, the subject was invited to look at some of the eyeblink responses, and to ask questions about the experiment.

All statistical analyses, both overall analyses and paired comparisons, were performed using the BMDP4V program, with conservative (Greenhouse-Geisser) degrees of freedom. The dependent variables were response probability, amplitude, and latency. Only responses with onsets within $20-100 \mathrm{msec}$ after stimulus onset were included, to eliminate nonreflexive responses. If the integrated EMG activity surpassed the baseline EMG activity (measured for $20 \mathrm{msec}$ after stimulus onset on each trial) within 20-100 msec after stimu- lus onset, a response onset was said to have occurred. This increase was defined as a change of at least 2 arbitrary units occurring within $5 \mathrm{msec}$, with the maximum sensitivity of the EMG recording equipment being $0.45 \mu \mathrm{V}$ per arbitrary unit. Of course, response onset is partially determined by the sensitivity of the response measurement equipment, noise levels, and sampling sensitivity, but the baseline EMG level (when the subject holds the head still and relaxes) is minimal, and even small responses can be detected if they occur. Response latency was the time between stimulus onset and response onset. The peak of the response was the point at which the EMG stopped increasing and began to return to baseline, when this point was followed by at least $15 \mathrm{msec}$ of no further increase in EMG activity. Response amplitude was the difference between the EMG level at response onset and peak, measured in arbitrary units and then converted to voltage. If the EMG signal during the response window (20-100 msec after stimulus onset) did not deviate from that present during the baseline period before stimulus onset, a failure to respond was recorded. Response probability was calculated as the number of responses that occurred divided by the number of trials on which a response could have been recorded, within each stimulus condition for each subject. (See Blumenthal \& Goode, 1991, for a more detailed description of these response measures.)

\section{RESULTS}

Three levels of data analysis were conducted-one involving measures of the startle response in the control (noprepulse) condition (elicitation), a second involving the comparison between responding in control and prepulse conditions (modification), and a third in which responding was compared between various prepulse conditions (relative modification). For analyses of startle response elicitation, the between-subjects variables were handedness and gender, and the within-subjects variable was dominance (whether the prepulses were being delivered to the subject's dominant or nondominant hand in the modification conditions). In the modification and relative modification analyses, the between-subjects variables were handedness and gender, and the within-subjects variables were dominance and prepulse frequency.

Startle response amplitude, probability, and latency to the 85-dB control stimuli were not significantly affected by gender or handedness (see Figures 1,2, and 3). Response amplitude and latency were not affected by dominance, but a significant effect of dominance was found for response probability $[F(1,16)=5.61, p<.05]$. This was due to lower probability when the nondominant hand was in position to receive prepulses than when the dominant hand was in position, even though no prepulses were presented in the control condition.

Relative to what occurred in the control condition, the prepulses caused increased response amplitude and decreased response latency to the startle stimulus in all conditions ( $p<.05$, using BMDP4V MANOVA comparisons), illustrating facilitation of these two response measures. The prepulses had no significant effect on the probability of a response to the startle stimulus.

Analysis of response latency to the startle stimulus preceded by a prepulse showed a significant main effect of prepulse frequency $[F(1,16)=7.78, p<.05]$, with 


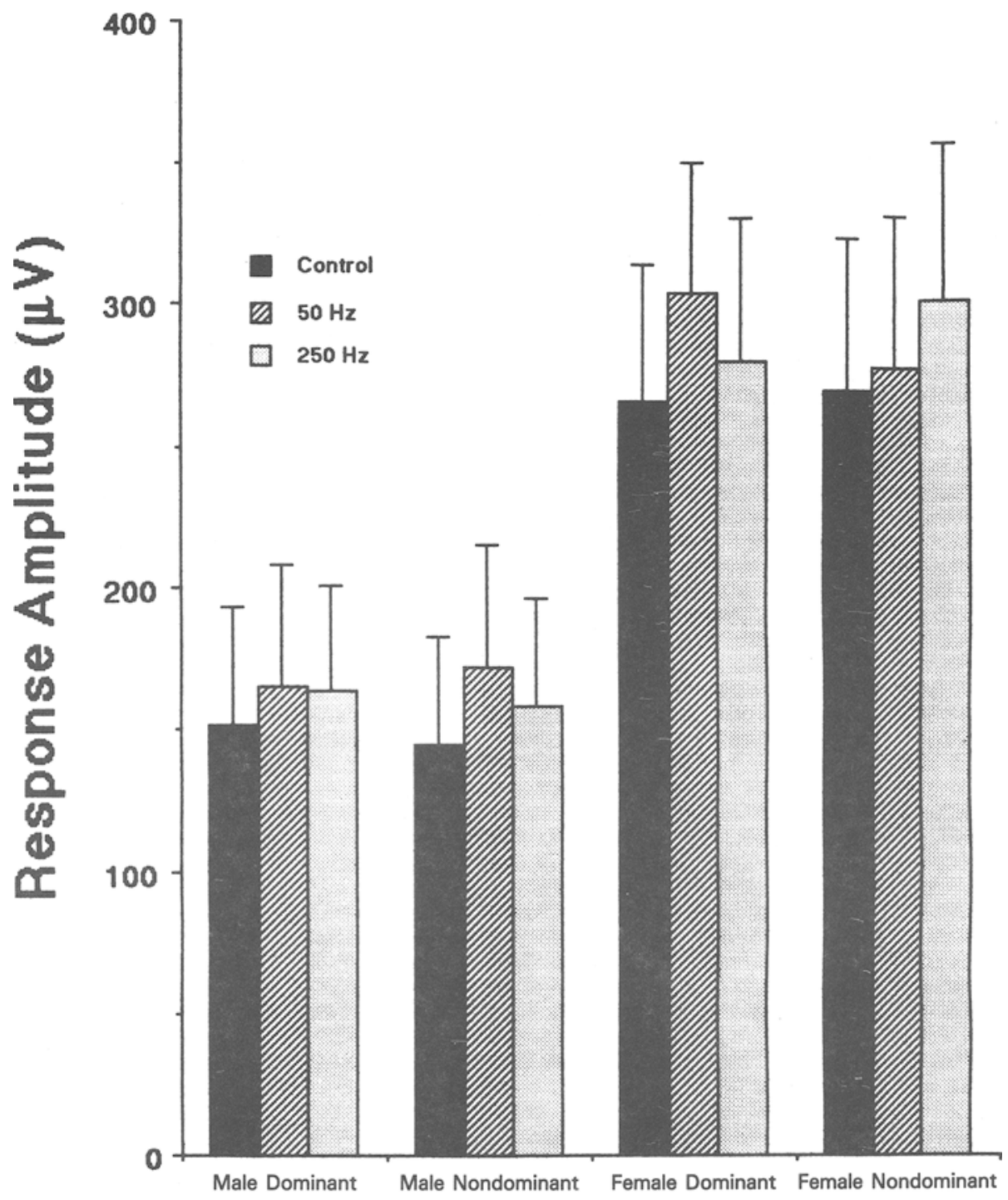

\section{Subject Gender and Dominance}

Figure 1. Response amplitude modification as a function of prepulse condition, for dominant and nondominant hands of males and females.

faster responding when the low-frequency prepulse was presented. No main effects of prepulse frequency were found for response probability or amplitude. However, for response amplitude, a three-way interaction between prepulse frequency, gender, and dominance reached significance $[F(1,16)=8.31, p<.05]$. Further analysis showed no effect of either dominance or prepulse frequency, or their interaction, for males, but a significant interaction between dominance and prepulse frequency for females $[F(1,9)=7.45, p<.05]$. For females, presenting the low-frequency prepulse to the dominant hand yielded a response amplitude similar to that obtained with presentation of the high-frequency prepulse to the nondominant hand. Response amplitude was lower in the other two conditions (low-frequency prepulse presented to the nondominant hand and high-frequency prepulse presented to the dominant hand), although these conditions yielded response amplitudes similar to each other.

The same analysis of response latency to the startle stimulus preceded by a prepulse mentioned in the preceding paragraph showed a significant main effect of dominance $[F(1,16)=6.68, p<.05]$, with faster respond- 


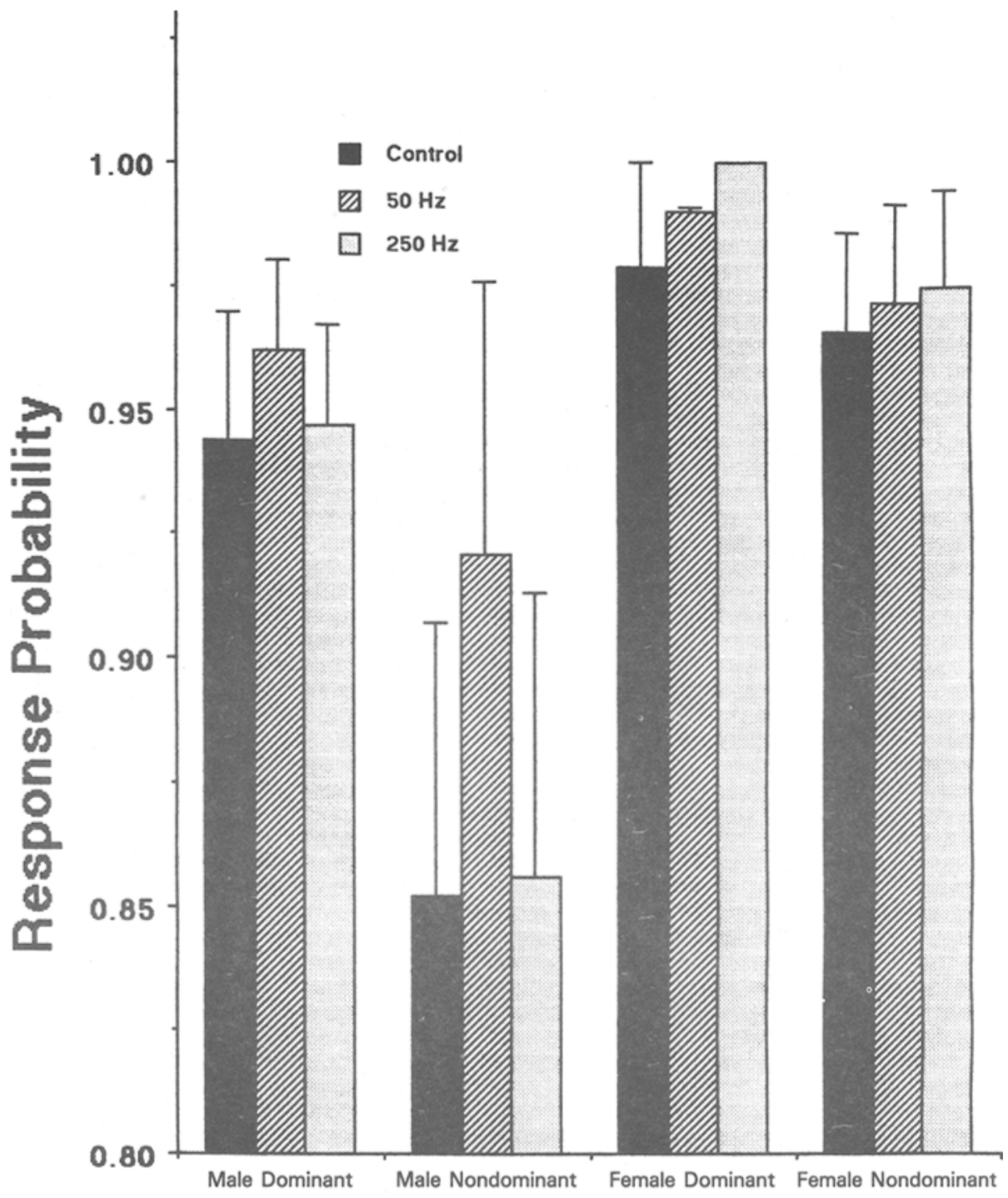

\section{Subject Gender and Dominance}

Figure 2. Response probability as a function of prepulse condition, for dominant and nondominant hands of males and females.

ing when the prepulse was presented to the dominant hand. For response probability, a significant main effect of dominance was also found $[F(1,16)=5.33, p<.05]$, as was a dominance $\times$ handedness interaction $[F(1,16)=6.76$, $p<.05]$. (See Figure 4.) Responding in left-handers was equally frequent, regardless of whether the prepulses were applied to the dominant or the nondominant hand. This same rate of responding was seen in right-handers when prepulses were applied to the dominant hand. When prepulses were applied to the nondominant hand of right- handed subjects, however, the rate of responding was lower.

A significant effect of gender was found for vibrotactile threshold $[F(1,16)=4.61, p<.05]$, with females tending to have lower vibrotactile thresholds than males (for females, $M=1.72 \mathrm{~dB}$, and for males, $M=3.14 \mathrm{~dB}$, relative to $1.0 \mu \mathrm{m}$ of displacement). Analysis of probability of response to the startle stimulus preceded by a prepulse showed a significant gender effect $[F(1,16)=$ $5.76, p<.05$ ], with responding being more probable for 


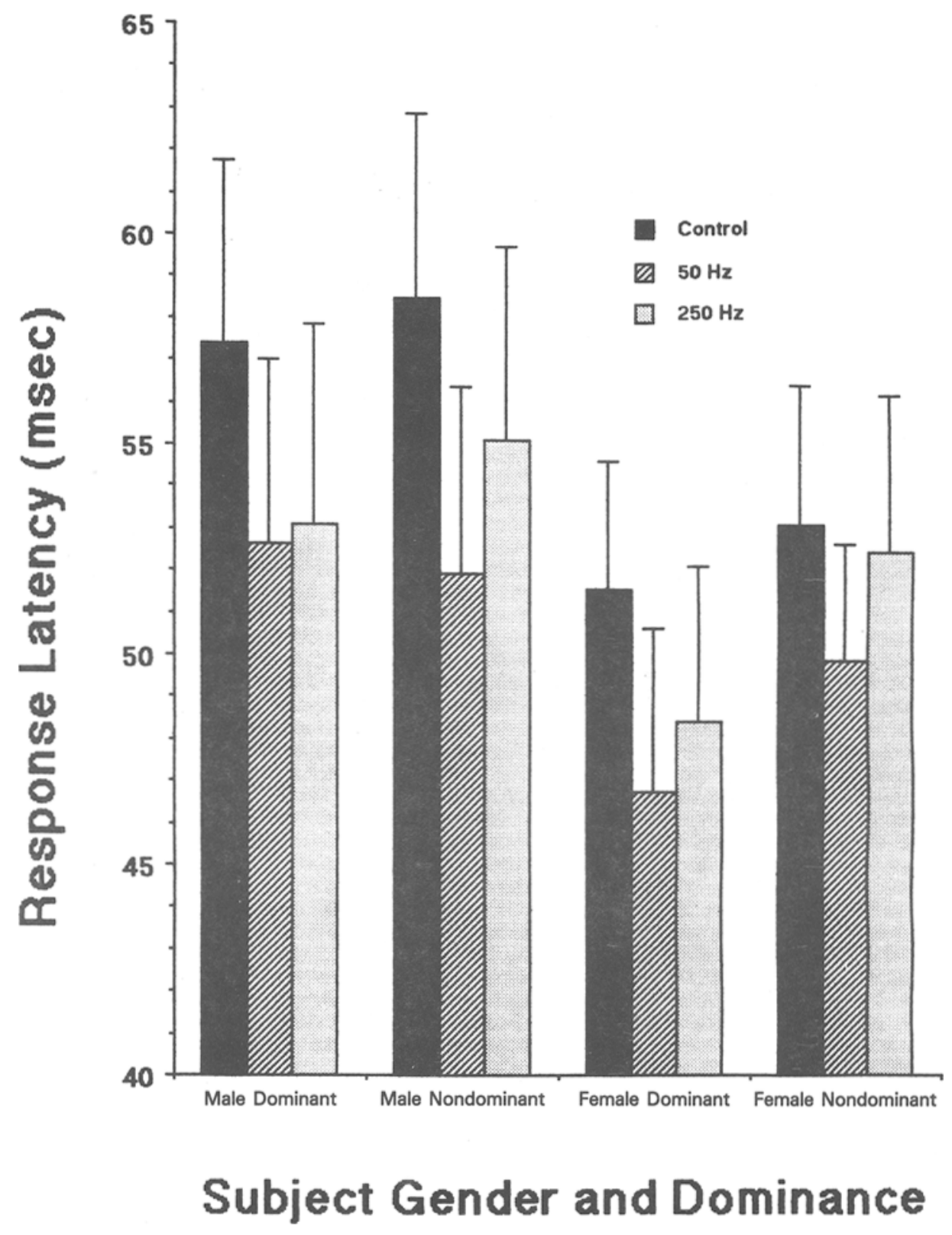

Figure 3. Response latency modification as a function of prepulse condition, for dominant and nondominant hands of males and females.

females than for males when a prepulse was presented. No main effects of gender were found for response amplitude or latency.

\section{DISCUSSION}

In the present study, vibrotactile prepulses at a lead time of $50 \mathrm{msec}$ facilitated the startle reflex to an acoustic stimulus, as was shown by increased response amplitude and decreased response latency. Using vibrotactile and acoustic stimuli similar to those of the present study,
Blumenthal and Gescheider (1987) found the same effects, and Blumenthal and Tolomeo (1989) found similar latency facilitation, but no amplitude facilitation at a 50-msec lead time (however, they did show amplitude facilitation at a 25 -msec lead time). Response probability was not facilitated by the prepulses, possibly because of a ceiling effect, in that response probability was so high in the control condition that further increases (facilitation) would not be measurable (see Blumenthal \& Tolomeo, 1989).

In some previous studies, gender differences in startle responding have been found (Blumenthal \& Gescheider, 


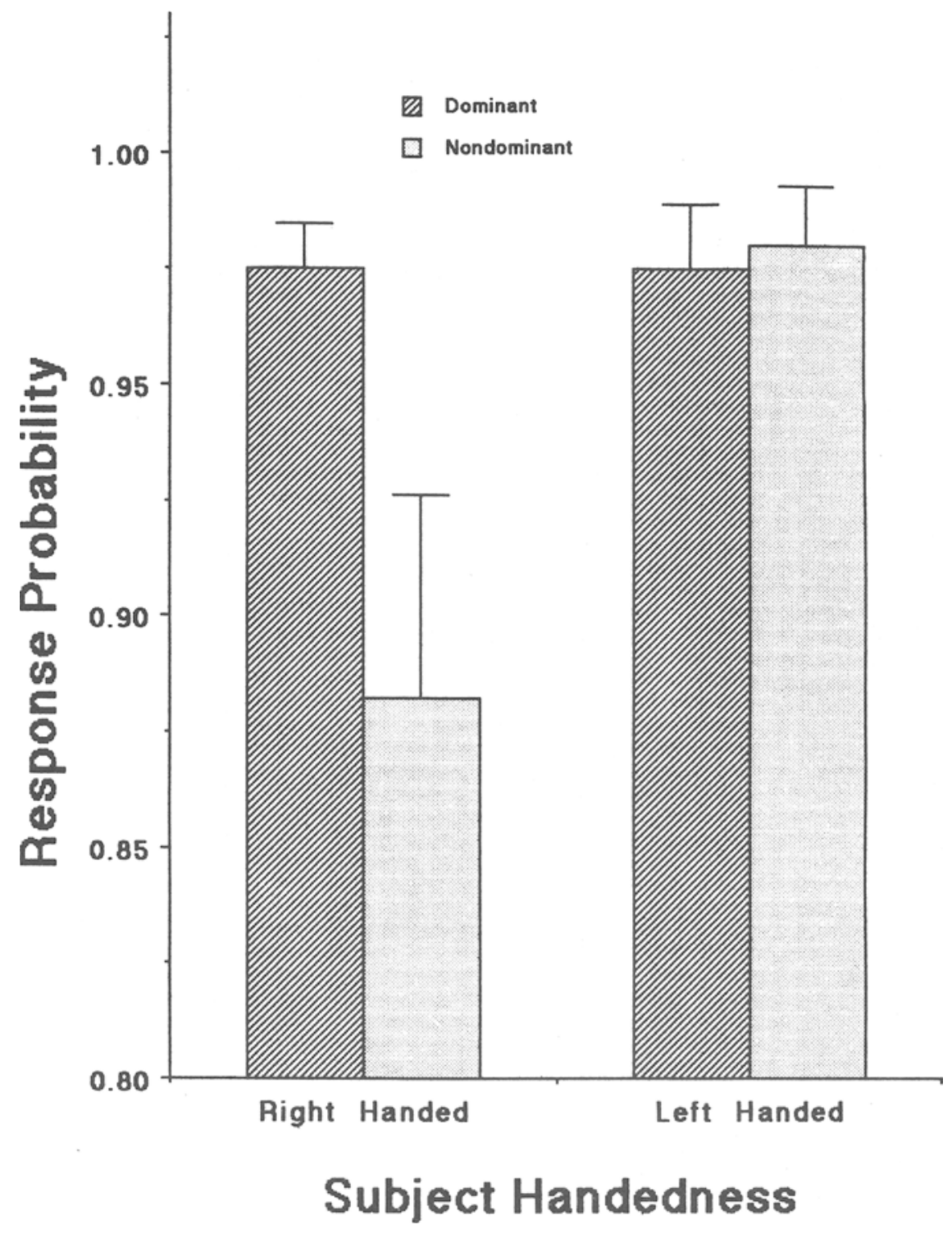

Figure 4. Response probability as a function of handedness and dominance.

1987; Zelson \& Simons, 1986). In the present study, females showed greater sensitivity to vibrotactile stimuli, in the form of lower thresholds, than did males. The difference in vibrotactile threshold between males and females may be explained by an effect found by Gescheider, Verrillo, McCann, and Aldrich (1984), who showed that the threshold for a $250-\mathrm{Hz}, 700$-msec vibrotactile stimulus in females differed over the course of their menstrual cycle. They did not find this for $15-\mathrm{Hz}$ vibrotactile stimuli, but it is still possible that the prepulses used in the present study are subject to this menstrual cycle effect. Another finding of the present study was that females were more likely to respond to a startle stimulus than were males, but this gender effect appeared only on trials on which a prepulse was presented, since response probability on control trials showed no gender differences.
An unexpected finding was the fact that simply placing the nondominant hand on the desk that held the vibrotactile device resulted in lower response probability on control trials. The desks in which the subject sat, and through which the vibrator contactor protruded, were wooden school desks in common use a few decades ago, and these desks were identical in all respects other than the transposition of left and right. The positioning of the subject was similar but reversed when the dominant versus the nondominant hand was resting on the desk. One speculative explanation for the unusual finding is that immobilization of the nondominant hand, obtained by asking the subject not to move it throughout the session, decreases overall reflex excitability, whereas this decrease in excitability does not occur when the dominant hand is immobilized. On prepulse trials, presenting prepulses to the 
nondominant hand (which necessitated having the hand resting on the desk) resulted in lower probability, but only in right-handers. For left-handers, response probability was equally high, no matter which hand was immobilized. In fact, this was the only effect of handedness found in this study. If there is some genuine reason for decreased response probability when the nondominant hand is immobilized, it is curious that this tendency only occurred with right-handers.

Response latency has been described as the best measure of the motor output limb of the startle reflex (Britt \& Blumenthal, 1991; Graham \& Murray, 1977), and this motor output was facilitated by the presentation of the vibrotactile prepulses. This facilitation was more pronounced when prepulses were presented to the dominant hand, suggesting that processing of the prepulses may have been more effective when they were presented to the dominant hand. However, the hypothesis that the prepulse information travels to the brainstem more rapidly from the dominant hand than the nondominant hand of right-handers is argued against by the findings of Tan (1985), who showed that nerve conduction velocities do not differ between the right and left arms of right- and left-handed people.

Also, latency facilitation was more pronounced when the $50-\mathrm{Hz}$ prepulse was presented than when the $250-\mathrm{Hz}$ prepulse was presented. Vibrotactile stimuli of these two frequencies are believed to activate different sensory receptors, with Pacinian corpuscles activated by $250-\mathrm{Hz}$ stimulation, and non-Pacinian receptors activated by the 50-Hz stimuli (Bolanowski, Gescheider, Verrillo, \& Checkosky, 1988; Sherrick, Cholewiak, \& Collins, 1990). An analogous effect was seen by Blumenthal and Gescheider (1987), who used vibrotactile prepulses ranging from $4 \mathrm{~dB}$ below threshold to $20 \mathrm{~dB}$ above threshold to modify the acoustic startle response. They found that as prepulse intensity increased, the effect of the prepulse on response amplitude became greater. Greater startle modification as prepulse "effectiveness" increases, usually indicated by increased intensity, is a common finding (Anthony, 1985; Graham \& Murray, 1977; Hoffman \& Ison, 1980).

The use of a vibrotactile prepulse in research involving the modification of the startle response is a relatively recent development. As in previous studies, cross-modal facilitation of startle eyeblink amplitude and latency were found in the present study. Also, the present study suggests that the effects of these prepulses can be influenced by the gender and handedness of the subjects, the frequency of the vibrotactile prepulse, and whether the prepulse is presented to the dominant or the nondominant hand.

\section{REFERENCES}

ANTHONY, B. J. (1985). In the blink of an eye: Implications of reflex modification for information processing. In P. K. Ackles, J. R. Jennings, \& M. G. H. Coles (Eds.), Advances in psychophysiology (Vol. 1, pp. 167-218). Greenwich, CT: JAI Press.
Blumenthal, T. D., \& Gescheider, G. A. (1987). Modification of the acoustic startle reflex by a tactile prepulse: The effects of stimulus onset asynchrony and prepuise intensity. Psychophysiology, 24, 320-327.

Blumenthal, T. D., \& GoOde, C. T. (1991). The startle eyeblink response to low intensity acoustic stimuli. Psychophysiology, 28, 296-306.

Blumenthal, T. D., \&olomeo, E. A. (1989). Bidirectional influences of vibrotactile stimuli on modification of the human acoustic startle reflex. Psychobiology, 17, 315-322.

Boelhouwer, A. J. W., Teurungs, R. J. M. A., B Bunia, C. H. M. (in press). The effect of an acoustic warning stimulus upon the electrically elicited blink reflex in humans. Psychophysiology.

Bolanowski, S. J., Gescheider, G. A., Verrillo, R. T., \& CHECkosky, C. M. (1988). Four channels mediate the mechanical aspects of touch. Journal of the Acoustical Society of America, 84, 1680-1694.

Britt, T. W., \& Blumenthal, T. D. (1991). Motoneuronal insensitivity in extraverts as revealed by the startle response paradigm. Personality \& Individual Differences, 12, 387-393.

Davis, M. (1984). The mammalian startle response. In R. C. Eaton (Ed.), Neural mechanisms of startle behavior (pp. 287-351). New York: Plenum.

Davis, M., Gendelman, D. S., Tischler, M. D., \& Gendelman, P. M. (1982). A primary acoustic startle circuit: Lesion and stimulation studies. Journal of Neuroscience, 2, 791-805.

Fogliani, A. M., Fogliani-Messina, T. M., Barletta, F., \& CARUSO, G. (1982). Hemispheric functionality patterns between dextrals and sinistrals in tactile-visual tasks at lower or higher levels of mental processes. Perceptual \& Motor Skills, 55, 291-297.

Gescheider, G. A., Verrillo, R. T., McCann, J. T., Aldrich, E. M. (1984). Effects of the menstrual cycle on vibrotactile sensitivity. Perception \& Psychophysics, 36, 586-592.

GRAHAM, F. K. (1975). The more or less starting effects of weak prestimulation. Psychophysiology, 12, 238-248.

Graham, F. K. (1980). Control of reflex blink excitability. In R. F. Thompson, L. H. Hicks, \& V. B. Shvyrkov (Eds.), Neural mechanisms of goal-directed behavior and learning (pp. 511-519). New York: Academic Press.

GrahaM, F. K., \& MURRAY, G. M. (1977). Discordant effects of weak prestimulation on magnitude and latency of the reflex blink. Physiological Psychology, 5, 108-114.

Haude, R. H., Morrow-Tlucak, M., Fox, D. M., Pickard, K. B. (1987). Differential visual field-interhemispheric transfer: Can it explain sex and handedness differences in lateralization? Perceptual \& Motor Skills, 65, 423-429.

HoffMAN, H. S., IsON, J. R. (1980). Reflex modification in the domain of startle: I. Some empirical findings and their implications for how the nervous system processes sensory input. Psychological Review, 87, 175-189.

LeItNer, D. S., Cohen, M. E. (1985). Role of the inferior colliculus in the inhibition of acoustic startle in the rat. Physiology \& Behavior, 34, 65-70.

Leirner, D. S., Powers, A. S., Hoffman, H. S. (1979). The neural system for the inhibition of startle. Bulletin of the Psychonomic Society, 14, 410-412.

Leitner, D. S., Powers, A. S., \& Hofrman, H. S. (1980). The neural substrate of the startle response. Physiology \& Behavior, 25, 291-297.

Leitner, D. S., Powers, A. S., Stitt, C. L., \& Hoffman, H. S. (1981). Midbrain reticular formation involvement in the inhibition of acoustic startle. Physiology \& Behavior, 26, 259-268.

OLDFIELD, R. C. (1971). The assessment and analysis of handedness: The Edinburgh Inventory. Neuropsychologia, 9, 97-113.

Perelle, I. 8., Ehrman, L., \& ManowItz, J. W. (1987). Human handedness: The influence of learning. Perceptual \& Motor Skills, 53, 967-977.

PertovaAra, A., \& Linnonkoski, I. (1986). Tactile detection threshold determined with single sinusoidal mechanical pulses in the monkey skin. Perceptual \& Motor Skills, 63, 1180-1182. 
Reiter, L. A., \& Ison, J. R. (1977). Inhibition of the human eyeblink reflex: An evaluation of the sensitivity of the Wendt-Yerkes method for threshold detection. Journal of Experimental Psychology: Human Perception \& Performance, 3, 325-336.

Sherrick, C. E., Cholewiak, R. W., Collins, A. A. (1990). The localization of low- and high-frequency vibrotactile stimuli. Joumal of the Acoustical Society of America, 88, 169-179

TAN, U. (1985). Velocities of motor and sensory nerve conduction are the same for right and left arms in right- and left-handed normal people. Perceptual \& Motor Skills, 60, 625-626.

WrTELSON, S. F. (1985). The brain connection: The corpus callosum is larger in left-handers. Science, 229, 665-668.

Zelson, M. F., \& Simons, R. F. (1986). Sustained attention in Type A and Type B subjects: A blink reflex analysis. Psychophysiology, 23, 385-392.

\section{NOTE}

1. In order to assess the contribution of the sound of the movement of the vibrator to the acoustic environment, we activated the vibrator, without the subject's hand on the desk, and measured the amount of noise produced by the vibrator at a vibration intensity near our estimate of $20 \mathrm{~dB}$ above threshold (we used our own thresholds for this measure). The vibrator produced a sound of approximately $27 \mathrm{~dB} \mathrm{SPL}$, and the ambient room noise was approximately $25 \mathrm{~dB}$ SPL. With a hand covering the vibrator, as in the actual testing situation, the vibrator noise was not discernible from the room noise.

(Manuscript received July 16, 1990; revision accepted for publication May 23, 1991.)

\section{Forthcoming Psychobiology Articles}

The following is a list of forthcoming Psychobiology articles that are currently in press. They are given in approximate order of acceptance. Each entry includes the name and address of the author with whom to communicate for further prepublication information.

"The role of norepinephrine in the expression of learned olfactory neurobehavioral responses in infant rats" by R.M. Sullivan \& D.A. Wilson (R.M.S., Developmental Psychobiology Lab, Dept. of Psychology, Univ. of Oklahoma, Norman, OK 73019)

"Immune alterations induced by a conditioned aversive stimulus: Evidence for a time-dependent effect"' by D.T. Lysle \& K.A. Maslonek (D.T.L., Dept. of Psychology, Davie Hall, CB 3270, Univ. of North Carolina, Chapel Hill, NC 27599-3270)

" Serum corticosterone level predicts the magnitude of hippocampal primed burst potentiation and depression in urethaneanesthetized rats" by M.C. Bennett, D.M. Diamond, M. Fleshner, \& G.M. Rose (G.M.R., Medical Research, V.A. Adminis. Med. Ctr., 1055 Clermont St., Denver, CO 80220)

"Pretraining morphine impairs acquisition and performance in the Morris water maze: Motivation reduction rather than amnesia"' by R.K. McNamara \& R.W. Skelton (R.W.S., Dept. of Psychology, Univ. of Victoria, P.O. Box 3050, Victoria, BC, Canada V8W 3P5)
"Fluoxetine effects on retention of inhibitory avoidance: Enhancement by systemic but not intraamygdala injections" by I.B. Introini-Collison, S. To, \& J.L. McGaugh (I.B.I., Ctr. for the Neurobiology of Learning and Memory, Univ. of California, Irvine, CA 92717)

"Competitive and noncompetitive $\mathbf{N}$-methyl-D-aspartate (NMDA) antagonists, haloperidol, and scopolamine impair performance in a nonspatial operant discrimination task" by D.B. Clissold, J.W. Ferkany, \& M.J. Pontecorvo (D.B.C., Nova Pharmaceutical Corporation, 6200 Freeport Centre, Baltimore, MD 21224)

"Natural speech processing: An analysis using event-related brain potentials' ' by P.J. Holcomb \& H.J. Neville (P.J.H., Dept. of Psychology, Tufts Univ., Medford, MA 02155)

"Long-term effects of food deprivation: I. Impact on pain reactivity and shock-induced hypoalgesia" by P.A. Illich, A.R. Allen, \& J.W. Grau (P.A.I., Dept. of Psychology, Texas A\&M Univ., College Station, TX 77843)

"Open field and response flexibility measures in the rat" by B. Anderson (B.A., Dept. of Neurology, Univ. of Alabama, UAB Station, Birmingham, AL 35294-0007) 